\title{
MONTE CARLO SIMULATION APPROACH TO CALCULATE VALUE AT RISK: APPLICATION TO WIG20 AND MWIG40
}

\begin{abstract}
Aleksandra Helena Pasieczna
Wrocław University of Economics, Wrocław, Poland

e-mail: pasiecznapl@gmail.com

ORCID: 0000-0001-6867-3584

(C) 2019 Aleksandra Helena Pasieczna

This is an open access article distributed under the Creative Commons Attribution-NonCommercial-NoDerivs license (http://creativecommons.org/licenses/by-nc-nd/3.0/)

DOI: 10.15611/fins.2019.2.05

JEL Classification: G170

Abstract: This paper reports our estimates of the Value at Risk using Monte Carlo simulations for which we developed a computer program. Our approach involves obtaining Monte Carlo parameters by fitting real historical data of different periods to probability distributions. We applied the algorithm to the WIG20 and mWIG40 stock indices, and performed simulations for the Value at Risk at 95\% and $99 \%$ confidence intervals over six estimation periods ranging from 1 trading day to 250 trading days. This approach was evaluated using the percentage failures and the Kupiec Proportion of Failures test. Our results indicate that this method is highly influenced by the choice of past historical and estimation period lengths considered. Overall, we observed that the Monte Carlo computational scheme is a reliable method for quantifying VaR when parametrized well.
\end{abstract}

Keywords: Monte Carlo, Value at Risk, WIG20, mWIG40, Kupiec, simulations.

\section{Introduction}

The increase in computational power available to people has led to the growth of computational finance. Due to certain characteristics of some data sets, e.g. example incompleteness, or the objectives of the project, like stock price predictions, it was natural to merge analytical and numerical tools. One of the applications of computational finance is to perform risk analysis. The Value at Risk (VaR), recommended by the Basel II agreement [Basel II 2004], is frequently used as a market risk measure. As VaR helps quantify the potential loss of an investment and assigns a certain probability to the loss, it plays an important part in the finance industry. This forms our motivation to study VaR. In common usage, there are three ways to measure VaR - the historical method, the variance-covariance method, and the Monte Carlo simulations [Holton 2014]. 
The aim of this paper is to perform Monte Carlo computer simulations to measure the VaR for different investment periods, past period lengths, and with different confidence intervals. In the following section, we present the theoretical and computational tools used to estimate the VaR. Section 3. deals with the simulation results for the VaR with different parameters. Our results show that the Monte Carlo approach works best in estimating VaR at $95 \%$ and $99 \%$ with historical window of 500 trading days ( 2 years) for estimation windows of under one month. We also observe a dependence of the estimation window length and the historical period on the VaR. The approach presented here is very general and can be extended to different applications with appropriate parameters.

\section{Theory and computational methods}

In this section we briefly describe the theory used to construct our numerical model - Value at Risk, the Monte Carlo method, and the computer algorithm.

\subsection{Value at Risk}

We wish to measure the Value at Risk (VaR), which is defined as the maximum possible loss, or equivalently the most "negative" price change, whose probability is within a pre-defined confidence interval over a pre-defined time horizon (investment period). This can be better understood with this example: if a portfolio has a VaR of 700 PLN over the investment period of one week with confidence of $95 \%$, it implies that the portfolio has at most a 5\% chance of losing 700 PLN or more over a period of one week. Equivalently, there is a $95 \%$ chance that the losses over one week will not be greater than 700 PLN for the given portfolio.

This definition of VaR is non-constructive in that it specifies a property that VaR should have, but not on how to compute VaR. As a result, there are different ways proposed to compute it [Holton 2014]. Additionally the definition allows use of VaR in risk management and risk measurement. For our purposes, we use the VaR to measure the risk of the WIG20 and mWIG40 indices [WIG], which correspond to the 20 largest and the next 40 largest stocks respectively in terms of market capitalization, in the Warsaw Stock Exchange. The stocks within these indices would be a crucial part of investment portfolios within Poland by different portfolio managers, and so these indices provide a good application case study.

\subsection{Monte Carlo methods}

We chose the Monte Carlo method [Glasserman 2003] to simulate the WIG20 and mWIG40 values for the different investment periods of interest. The main advantage of this method is that one can simulate the different sources of uncertainty that affect these indices. 
Monte Carlo methods were initially developed for the physics and chemistry communities. The advantage to deal with probabilistic events, such as Brownian motion, was a major factor in using these methods in various areas of finance, such as corporate finance [Savvides 1994], portfolio optimization [Detemple et al. 2003], and risk analysis [Evans, Olson 1998]. These methods are widely used in dealing with quantities that have a high degree of uncertainty, and where traditional analytical ways might fail. Our approach uses Monte Carlo to simulate the uncertain price changes and the uncertainty is determined by real historical data.

Two major limitations of Monte Carlo methods in general are their sensitivity to the model hyper-parameters (distributions etc.), and the computational costs (multiple iterations and runs).

\subsection{Program algorithm}

Here we present the main essence of the program that calculates the VaR for the WIG20 and mWIG40 indices with Monte Carlo simulations. This program was fully implemented by us using the Python language. The libraries used for reading the data, fitting the data, simulating the prices, and plotting the results were 'pandas', 'numpy', 'scipy.stats.norm' and 'matplotlib.pyplot'.

- We chose the daily closing prices of the WIG20 and mWIG40 from 02 April 2007 to 22 December 2017 as the objects of study. The large number of datapoints provides a relatively large sample to test our program for different investment and historical period lengths.

- The uncertainty in the index value is assumed to appear through the relative price change over each day. In our computations, we confirmed the normal distributions of the relative price change, through the Shapiro-Wilk [Shapiro, Wilk 1965] and Kolmogorov-Smirnov [Stephens 2012] tests. We also observed that the percentage price changes have a mean of around $0 \%$ and a standard deviation of around $1 \%$. However, to better represent the trends in our data, for each 'buying' day we fit the mean and standard deviation of our normal distribution to the past (historical) mean and standard deviation for period lengths of 250, 500 and 1250 trading days. These correspond to learning periods of approximately 1, 2 and 5 years.

- For each investment period we consider (1, 5, 10, 22, 125 and 250 trading days), we simulated 50000 possible prices in the future for each historical period length. We emphasize that these prices are only hypothetical and are obtained by generating random numbers corresponding to a normal distribution with a mean and a standard deviation that was fit to the chosen past period length. For comparison all results will be shown from 2012 (to adjust for all past period lengths).

- We then sorted the price changes over the investment period in ascending order. The VaR for a given investment period and a given confidence interval is simply 
the percentile value of the price changes for that investment period. For example, the VaR for an investment period of 22 trading days, with the confidence interval of $95 \%$ is the $2500^{\text {th }}$ or the $(1-0.95) * 50000^{\text {th }}$ value of the sorted price changes over 22 trading days.

- To verify that the VaR obtained for the different investment periods follow the definition that the price changes will be above (loss = negative price change) the VaR with a probability given by the confidence interval, we performed backtesting. Backtesting is the process of comparing the actual price change over an investment period with the hypothetical (simulated) price change at the VaR over the corresponding investment period.

- Finally, all the different parameterizations of the model were evaluated using percentage crossings and the Kupiec Proportion of Failures (POF) test [Kupiec 1995].

\section{Simulation results}

This section deals with our Monte Carlo simulations for the VaR at different confidence intervals for the different estimation periods. Backtesting results for the $\mathrm{VaR}$ at confidence intervals of $95 \%$ and $99 \%$ over estimation periods of 1,5 , $10,22,125$ and 250 trading days are shown graphically. These chosen estimation periods correspond to investment periods of approximately one day, one week, two weeks, one month, six months and one year respectively. Like most investment risk measures, the price change is of more interest than the price itself, since, from the investor's perspective, profits and losses matter. For this reason, the figures plot theoretical VaR and actual price changes for comparative purposes.

In Figure 1 we plot the daily moving averages for different historical periods for the two indices of interest. We observe that longer time periods tend to produce smoother curves. However, longer time periods are less sensitive to 'recent' information, which can cause 'lags' in fitting the mean and standard deviation (see Figure 2). The latter effect can be seen in Figure 2, where a sudden drop in the blue curve (mid-2012) is shifted to the right and lessened in intensity in the two curves (mid-2013 and mid-2016 for the orange and green curves respectively).

Now we present the comparison curves between the estimated VaR and actual price changes. The actual price changes are plotted in red, and the Monte Carlo results are shown for historical periods of 250,500 and 1250 TD in the other colors. We highlight that each point on the red curves corresponds to actual price changes, and the points on the blue, orange and green curves correspond to price changes between real and estimated prices over the corresponding prediction period. The estimations were obtained from averages and standard deviations computed over the historical period.

$$
\begin{aligned}
& \Delta P_{M C}(t)=P_{\text {estimated }}(t)-P_{\text {actual }}(t-\text { PredictionPeriodInTD }), \\
& \Delta P_{\text {actual }}(t)=P_{\text {actual }}(t)-P_{\text {actual }}(t-\text { PredictionPeriodInTD }) .
\end{aligned}
$$



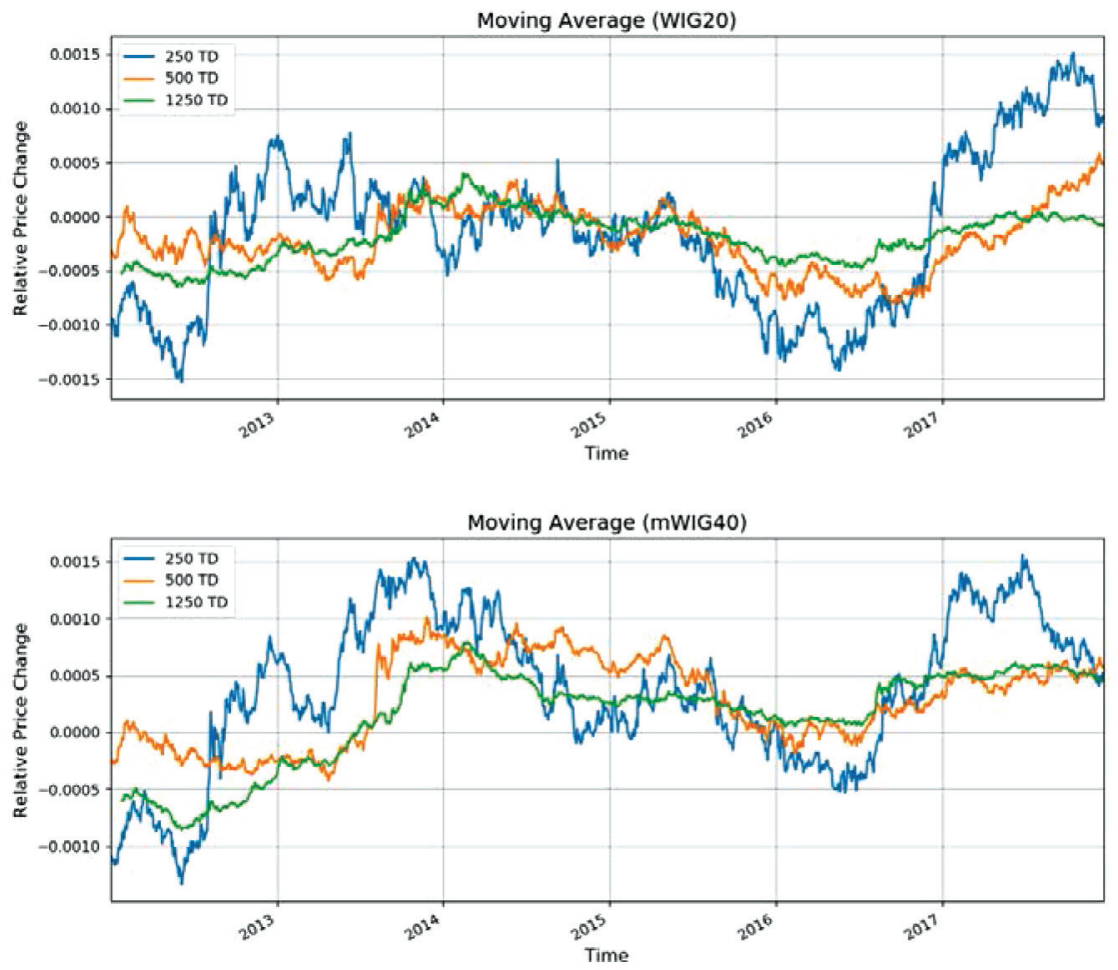

Fig. 1. Comparison of moving averages of relative price changes for different past period lengths for the WIG20 (top) and mWIG40 (below) indices

Source: own study.

For the sake of brevity, we restrict ourselves to showing the plots corresponding to prediction periods of 1, 10, 125 and $250 \mathrm{TD}$. These are chosen to represent prices changes and VaR curves over short, medium and long time-scales.

Figures 3, 5, 7, and 9 present our results for the VaR with 95 confidence intervals for the given indices with estimation periods of 1, 10, 125 and 250 TD respectively. We show our VaR results for the VaR with $99 \%$ confidence intervals respectively in Figures 4, 6, 8 and 10 for the chosen estimation periods.

Generally, we see that the simulated curves are below the actual price changes, indicating that our approach captures investment risk. We observe that the historical period of $250 \mathrm{TD}$ (blue) tends to be higher than that of $500 \mathrm{TD}$ (orange), which is above that of $1250 \mathrm{TD}$ (green). This implies that larger historical periods tend to overestimate the risk. It should be pointed out that our results are strictly valid within the time-period considered in the dataset. Further study of other indices and different time-periods might help to understand this behavior in more detail. 

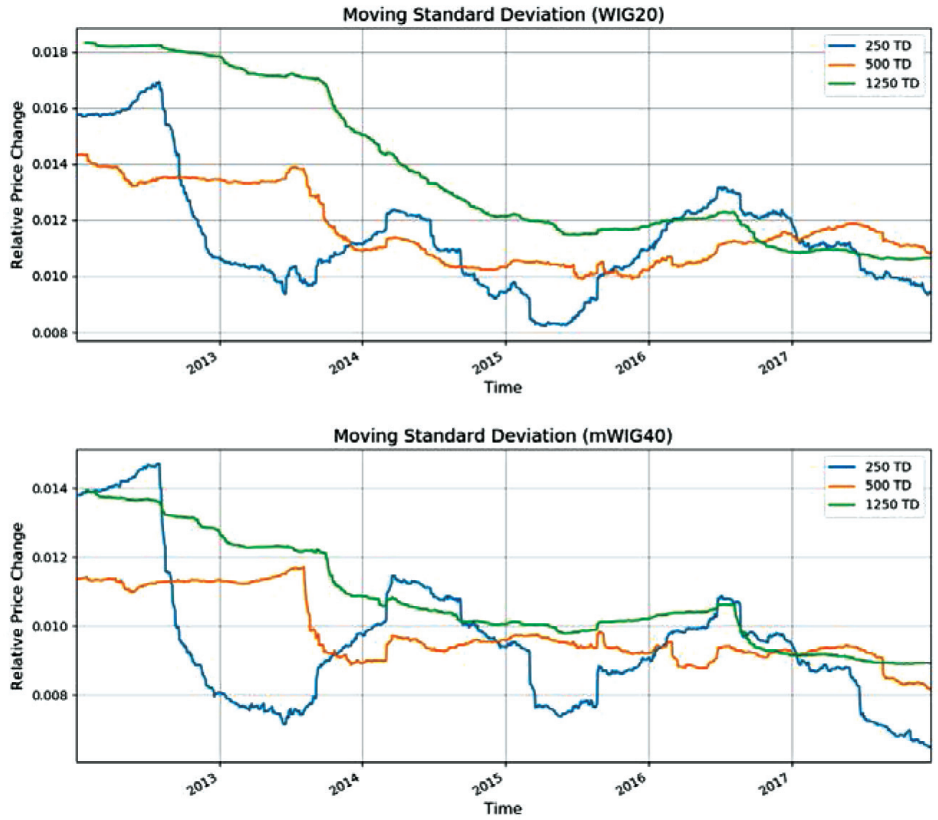

Fig. 2. Comparison of moving standard deviations of relative price changes for different past period lengths for the WIG20 (top) and mWIG40 (below) indices

Source: own study.
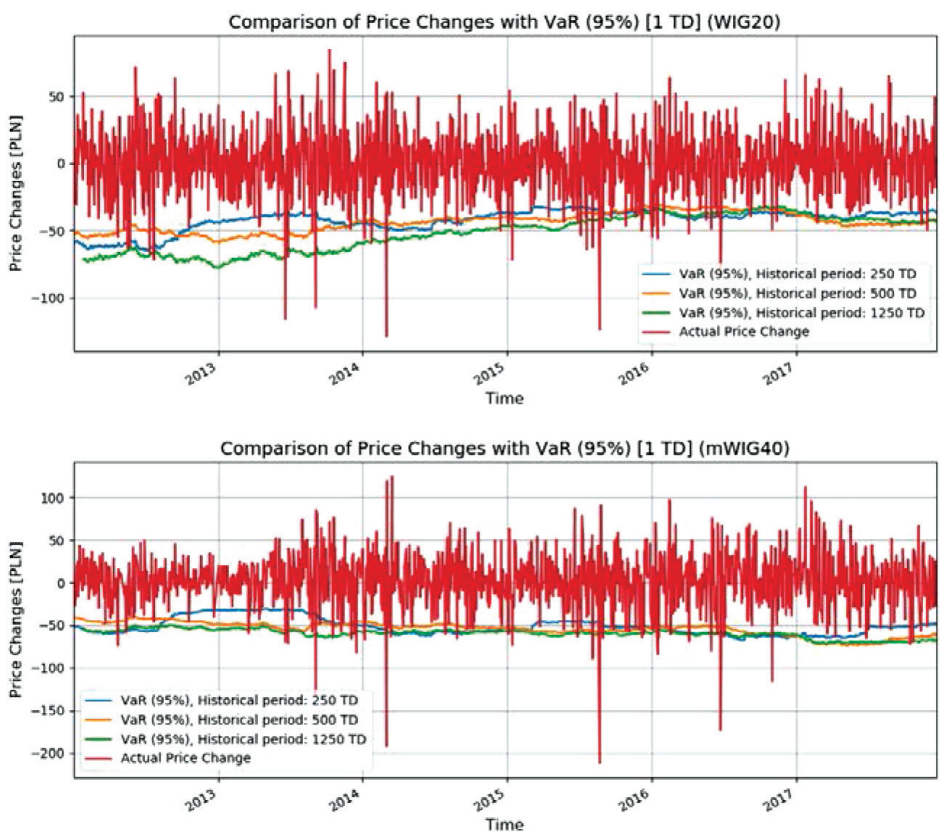

Fig. 3. Comparison of price changes with VaR (95\%) for different past period lengths over an estimation period of 1 trading day for the WIG20 (top) and mWIG40 (below) indices Source: own study. 

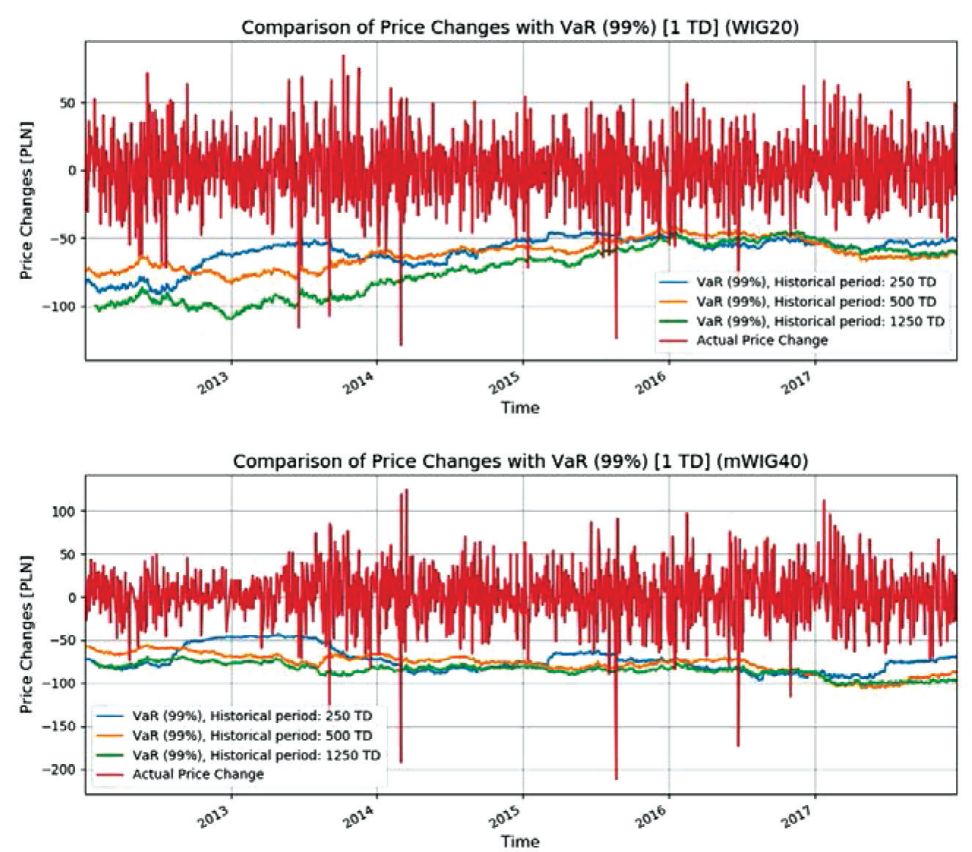

Fig. 4. Comparison of price changes with VaR (99\%) for different past period lengths over an estimation period of 1 trading day for the WIG20 (top) and mWIG40 (below) indices Source: own study.


Fig. 5. Comparison of price changes with VaR (95\%) for different past period lengths over an estimation period of 10 trading days for the WIG20 (top) and mWIG40 (below) indices Source: own study. 

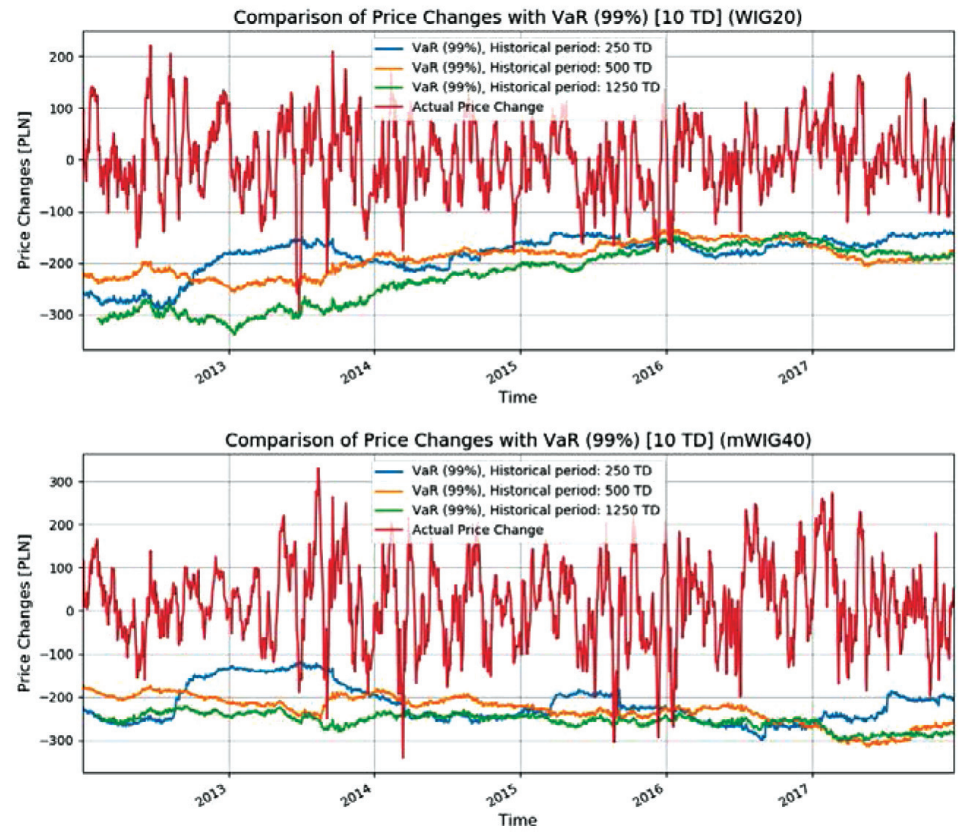

Fig. 6. Comparison of price changes with VaR (99\%) for different past period lengths over an estimation period of 10 trading days for the WIG20 (top) and mWIG40 (below) indices Source: own study.
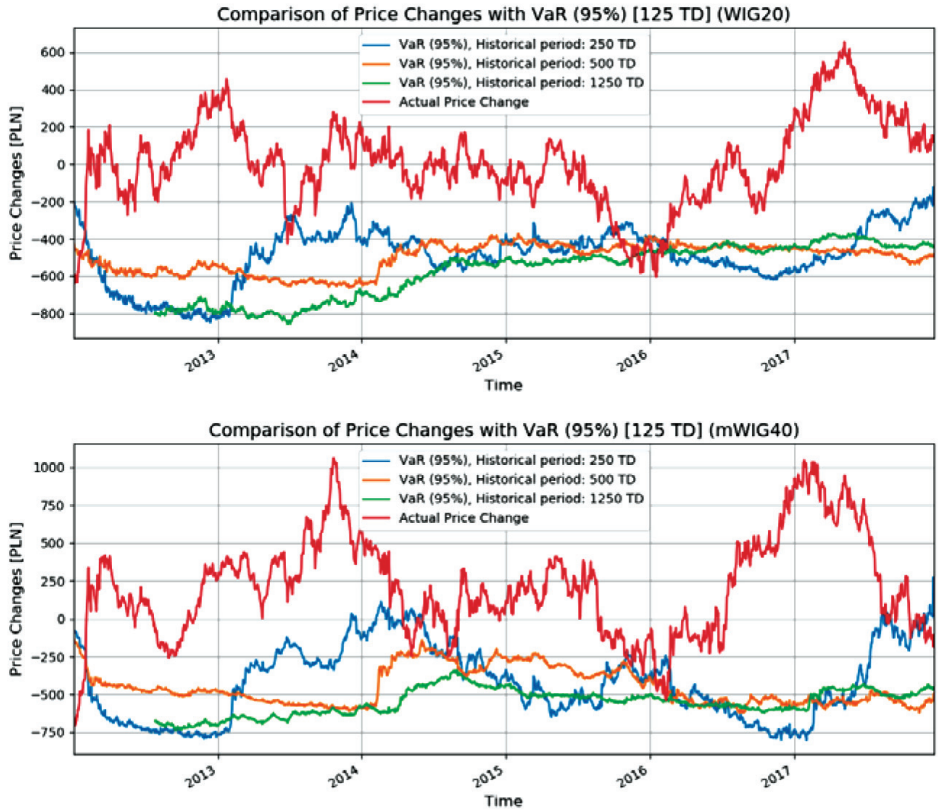

Fig. 7. Comparison of price changes with VaR (95\%) for different past period lengths over an estimation period of 125 trading days for the WIG20 (top) and mWIG40 (below) indices Source: own study. 

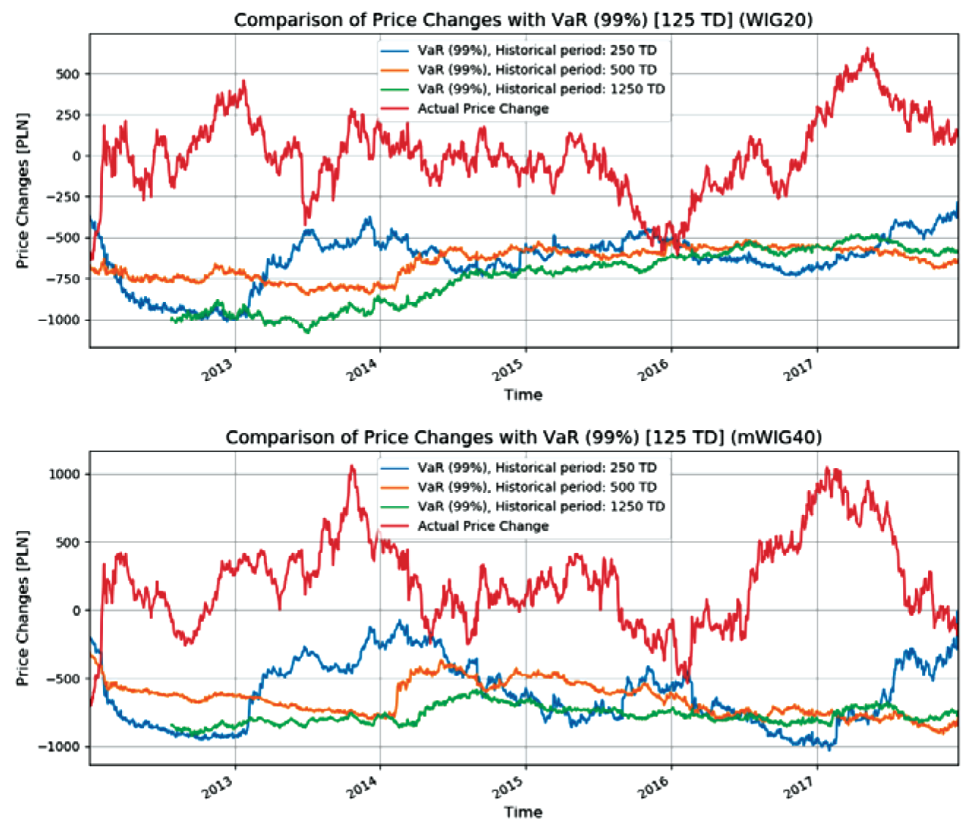

Fig. 8. Comparison of price changes with VaR (99\%) for different past period lengths over an estimation period of 125 trading days for the WIG20 (top) and mWIG40 (below) indices Source: own study.
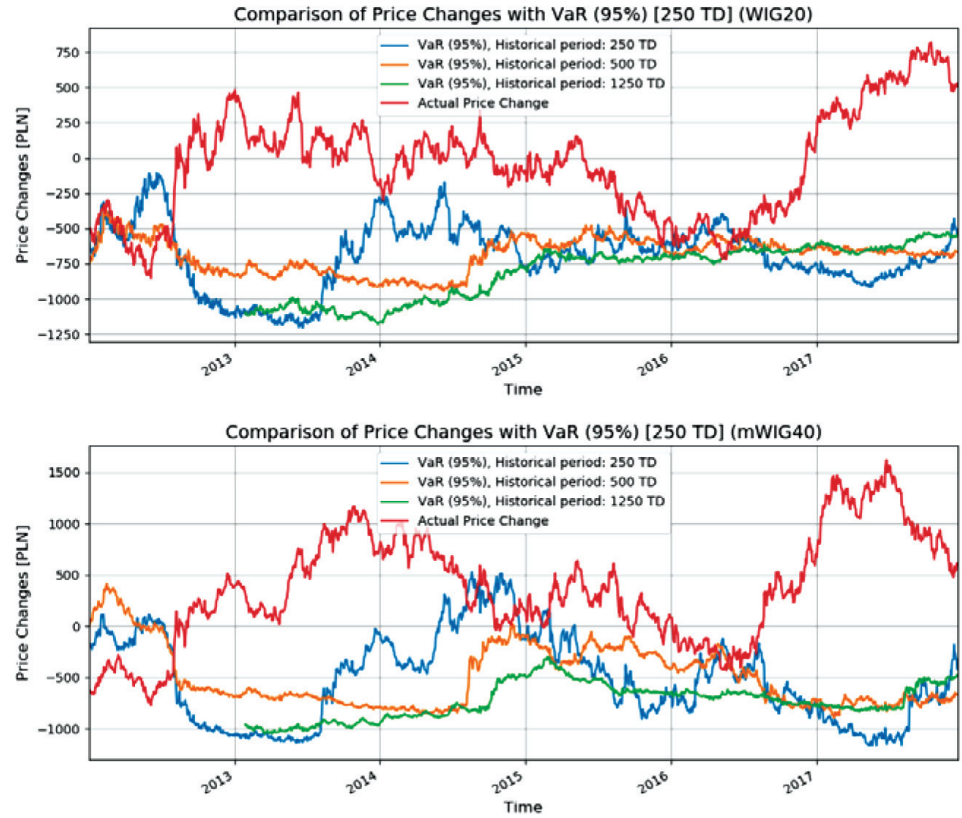

Fig. 9. Comparison of price changes with VaR (95\%) for different past period lengths over an estimation period of 250 trading days for the WIG20 (top) and mWIG40 (below) indices Source: own study. 

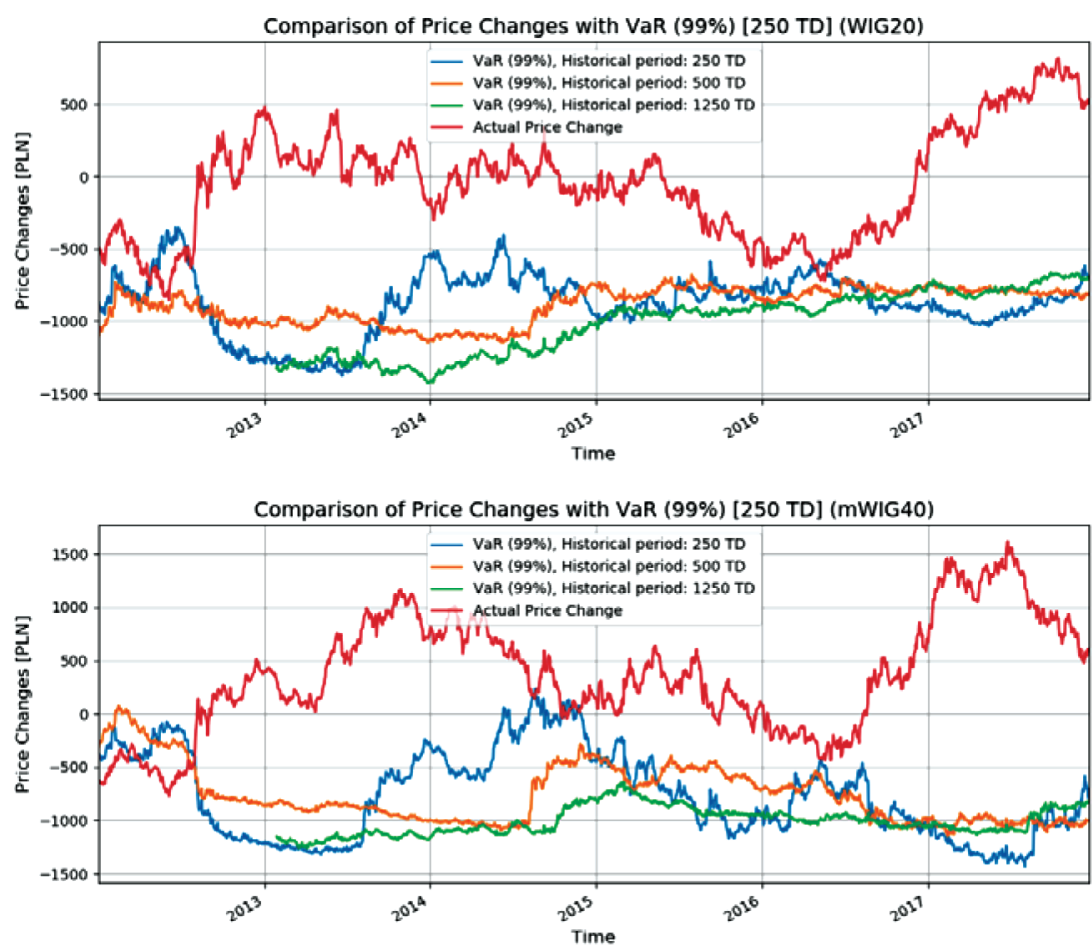

Fig. 10. Comparison of price changes with VaR (99\%) for different past period lengths over an estimation period of 250 trading days for the WIG20 (top) and mWIG40 (below) indices

Source: own study.

In all the figures shown, we observe that the VaR measure provides a lower threshold for the real (actual) price changes. For most of the estimation periods considered, the real price changes cross the two thresholds (95\% and 99\%) less than the corresponding confidence interval set by VaR. This leads us to believe that the $\mathrm{VaR}$ is a reliable measure of investment risk for the WIG20 and mWIG40 indices.

To obtain a more complete picture of our approach, it is important to compute the percentage of the real price changes crossing the thresholds set by VaR. For our purposes we present the Kupiec Proportion of Failures test along with the corresponding percentage crossings in parentheses.

The percentage crossings indicate that in the case of short historical periods ( 250 TD) used for obtaining the average and standard deviation, there are more crossings than expected with the VaR confidence intervals. As this period is increased to 500 and $1250 \mathrm{TD}$, the percentage crossings drop reaching 0 for many estimation periods. Thus, our computational algorithm, which combines Monte Carlo simulations with the parameters determined by the historical data, provides an independent VaR measure. 

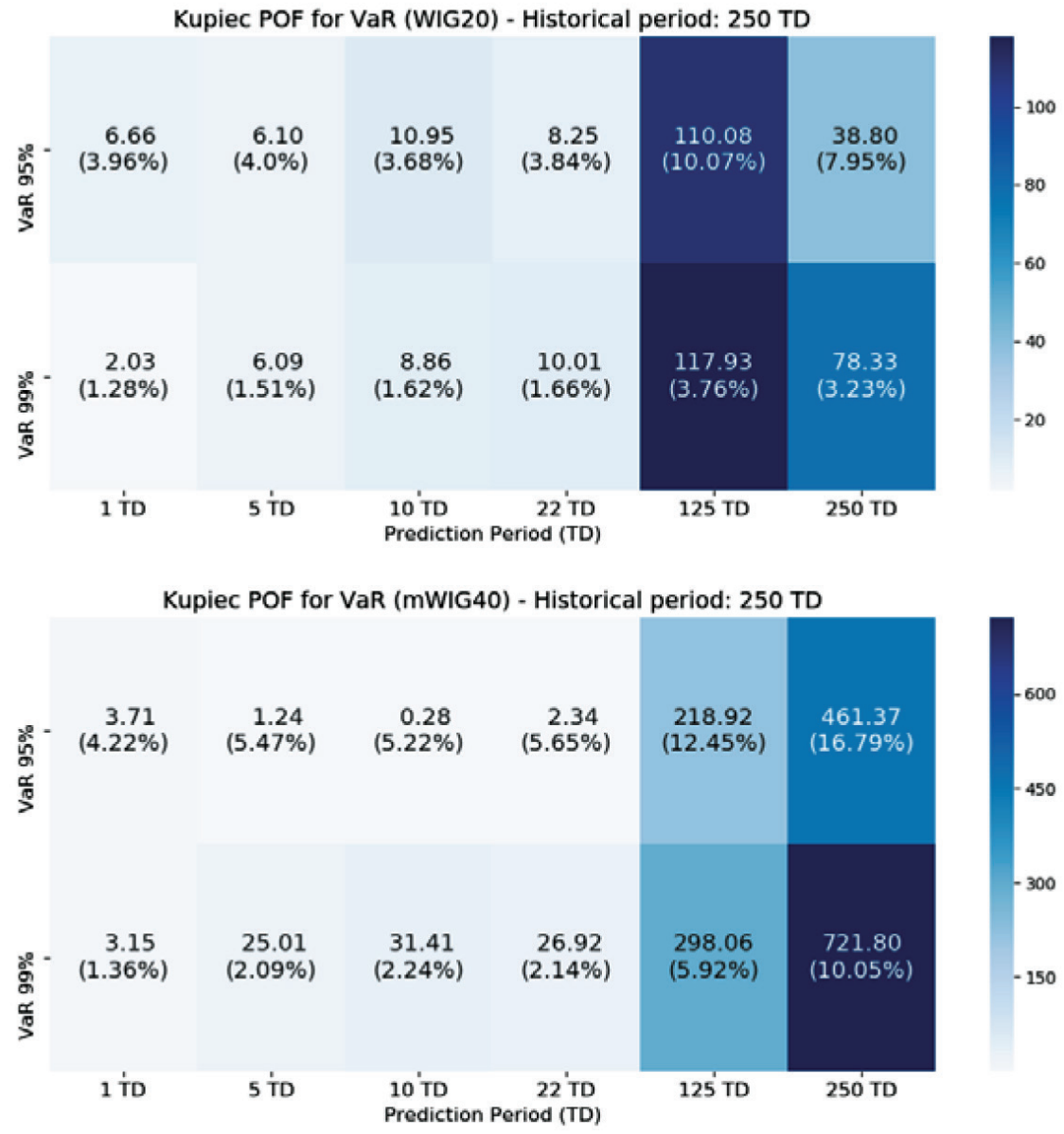

Fig. 11. Heatmap for Kupiec POF values for VaR (95\%) and VaR (99\%) for historical period of 250 trading days for the WIG20 (top) and mWIG40 (below) indices (the percentage crossings are provided in parentheses)

Source: own study.

On the basis of the Kupiec POF test, we observe that the Kupiec likelihood ratios of the models with the historical period of $250 \mathrm{TD}$ are relatively high, which when analyzed along with the percentage crossings, indicates that the models perform poorly when the prediction periods are above 125 TD. The best Kupiec likelihood ratios $(<1)$ are obtained for the VaR with $99 \%$ for historical period of $500 \mathrm{TD}$ and estimation periods of 1,5 and 10 TD for both indices. The Kupiec likelihood ratios for all estimation periods with the historical period of $1250 \mathrm{TD}$ are very high, which combined with the very low percentage crossings, indicates that the risk is overestimated in this model. 
Kupiec POF for VaR (WIG20) - Historical period: 500 TD
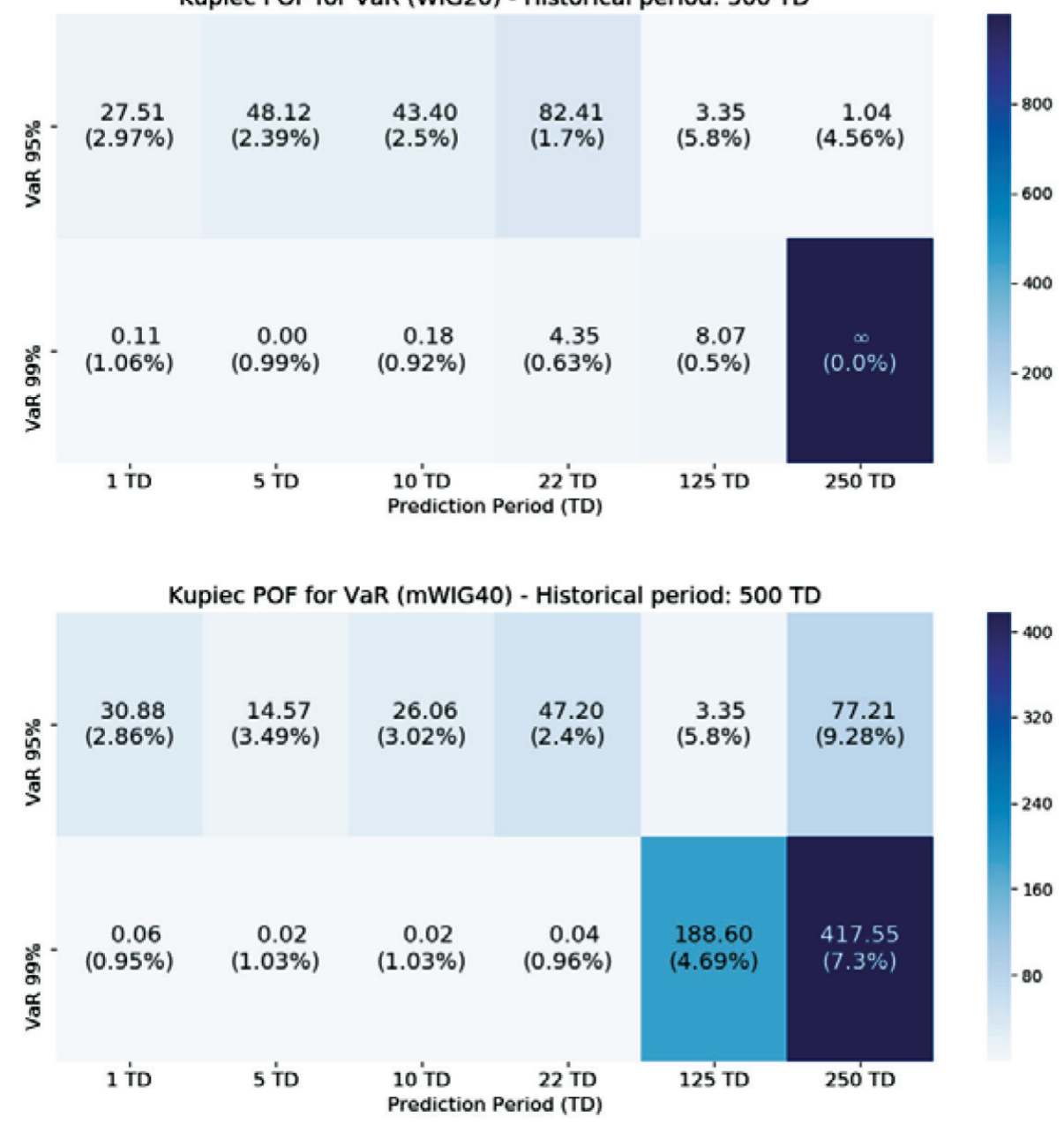

Fig. 12. Heatmap for Kupiec POF values for VaR (95\%) and VaR (99\%) for historical period of 500 trading days for the WIG20 (top) and mWIG40 (below) indices (the percentage crossings are provided in parentheses)

Source: own study. 

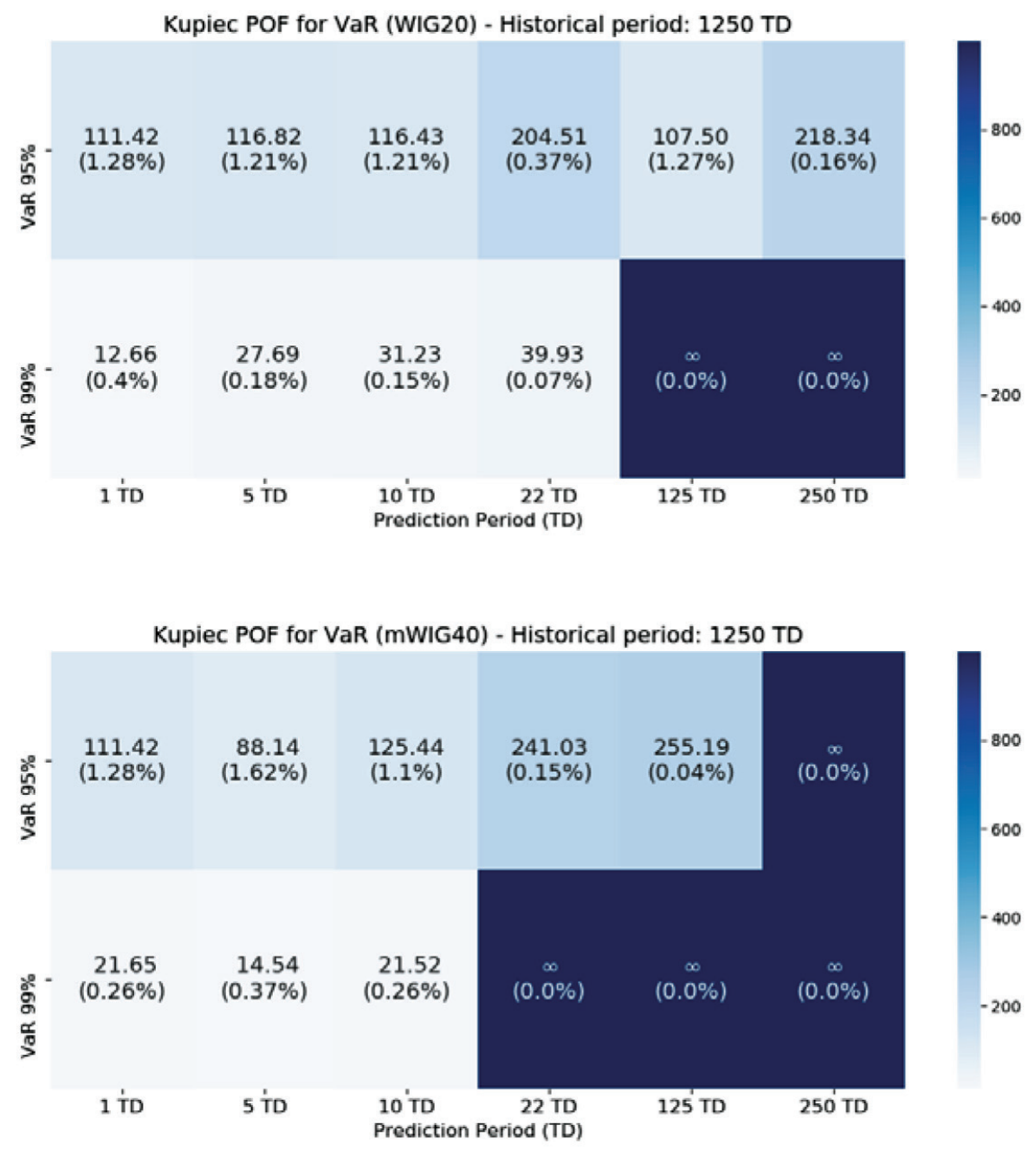

Fig. 13. Heatmap for Kupiec POF values for VaR (95\%) and VaR (99\%) for historical period of 1250 trading days for the WIG20 (top) and mWIG40 (below) indices (the percentage crossings are provided in parentheses)

Source: own study.

\section{Conclusions and perspectives}

In this work we have calculated the Value at Risk for different confidence intervals over different estimation periods using the Monte Carlo method. The VaR of the WIG20 and mWIG40 indices were computed at $95 \%$ and $99 \%$ confidence intervals 
over six estimation periods ranging from 1 to 250 trading days, with 50000 Monte Carlo iterations. The Monte Carlo parameters were obtained by fitting historical relative price change data of the indices of different historical period lengths to a normal distribution.

Our results show that the model works best for a historical time period of $500 \mathrm{TD}$ to fit the average and standard deviation for prediction windows of up to $22 \mathrm{TD}$. This implies that the approach works for relatively short prediction horizons compared to the historical time period. Counterintuitively to what one might expect, a longer historical time horizon degrades the Kupiec POF due to the overestimation of the risk. Additionally, there is no discernible pattern between the prediction window and the historical time window.

The program developed here is very general and can be easily adapted to study the Value at Risk at different confidence intervals over different estimation periods for any price index, based on different historical time periods. Additionally, one can easily modify the algorithm to obtain Monte Carlo simulations with any probability distribution, which might better reflect the real price changes. While this approach was used to estimate VaR, the general algorithm can also be extended for similar risk measurements.

In terms of perspectives, the study of different simulation time periods would help avoid over-fitting our model to specific trends or cycles. It would be fruitful to study the VaR for more stock indices and portfolios. The use of different probability distributions might help in establishing a stronger understanding, and eventually help in developing better investment strategies. Additional use of exponentialmoving averages instead of simple-moving averages to emphasize recent events would be helpful, as the model adapts quicker to new information, while reducing the dependence on long-past events.

\section{Bibliography}

Basel II, 2004, Basel II: International Convergence of Capital Measurement and Capital Standards: A Revised Framework, https://www.bis.org/publ/bcbs107.htm (12.01.2018).

Detemple J.B., Garcia R., Rindisbacher M., 2003, A Monte Carlo method for optimal portfolios, Journal of Finance, vol. 58, no. 1, pp. 401-446.

Evans J.R., Olson D.L., 1998, Introduction to Simulation and Risk Analysis, Prentice-Hall, Inc., New Jersey, USA.

Glasserman P., 2003, Monte Carlo Methods in Financial Engineering, Springer Science+Business Media, New York, USA.

Holton G.A., 2014, Value-at-Risk Theory and Practice, Second Edition (self-published), https://www. value-at-risk.net (15.01.2018).

Kupiec P.H., 1995, Techniques for verifying the accuracy of risk measurement models, The Journal of Derivatives, vol. 3, no. 2, pp. 73-84.

Savvides S.C., 1994, Risk analysis in investment appraisal, Project Appraisal Journal, vol. 9, no. 1. 
Shapiro S.S., Wilk M.B., 1965, An analysis of variance test for normality (complete samples), Biometrika, vol. 52, no. 3-4, pp. 591-611.

Stephens M.A., 2012, EDF statistics for goodness of fit and some comparisons, Journal of the American Statistical Association, vol. 69, no. 347, pp. 730-737.

WIG data https://stooq.pl (23.12.2017).

\section{METODA SYMULACJI MONTE CARLO W OBLICZANIU WARTOŚCI ZAGROŻONEJ RYZYKIEM (VAR): ZASTOSOWANIE DLA WIG20 I MWIG40}

Streszczenie: W niniejszym artykule przedstawiono oszacowanie wartości zagrożonej ryzykiem VaR za pomocą symulacji Monte Carlo, dla której stworzono program komputerowy. Podejście polega na uzyskaniu parametrów Monte Carlo przez dopasowanie rzeczywistych danych historycznych z różnych okresów do rozkładów prawdopodobieństwa. Zastosowano ten algorytm dla indeksów giełdowych WIG20 i mWIG40, dla dwóch przedziałów ufności - wynoszących 95\% i 99\%, w sześciu okresach szacunkowych, które wynosiły od 1 do 250 dni pracujących. Aby uzyskać ocenę wyników symulacji, analizowano procentowy udział niepowodzeń oraz test Kupca. Wyniki te wskazują na duży wpływ rozpiętości zakresu danych historycznych, a także długości okresów szacunkowych na ocenę symulacji. Stwierdzono, iż schemat obliczeniowy metody Monte Carlo, przy odpowiedniej parametryzacji, jest wiarygodną metodą określania wartości zagrożonej ryzykiem VaR.

Słowa kluczowe: Monte Carlo, wartość zagrożona ryzykiem, WIG20, mWIG40, Kupiec, symulacje. 